\title{
Induction of secondary metabolism of Aspergillus terreus ATCC 20542 in the batch bioreactor cultures
}

\author{
Tomasz Boruta $^{1} \cdot$ Marcin Bizukoje $^{1}$
}

Received: 21 July 2015 /Revised: 20 September 2015 / Accepted: 6 November 2015 / Published online: 25 November 2015

(C) The Author(s) 2015. This article is published with open access at Springerlink.com

\begin{abstract}
Cultivation of Aspergillus terreus ATCC 20542 in a stirred tank bioreactor was performed to induce the biosynthesis of secondary metabolites and provide the bioprocessrelated insights into the metabolic capabilities of the investigated strain. The activation of biosynthetic routes was attempted by the diversification of process conditions and growth media. Several strategies were tested, including the addition of rapeseed oil or inulin, changing the concentration of nitrogen source, reduction of chlorine supply, cultivation under saline conditions, and using various aeration schemes. Fifteen secondary metabolites were identified in the course of the study by using ultra-high performance liquid chromatography coupled with mass spectrometry, namely mevinolinic acid, 4a,5-dihydromevinolinic acid, $3 \alpha$-hydroxy-3,5dihydromonacolin $\mathrm{L}$ acid, terrein, aspulvinone $\mathrm{E}$, dihydroisoflavipucine, $(+)$-geodin, $(+)$-bisdechlorogeodin, $(+)$-erdin, asterric acid, butyrolactone I, desmethylsulochrin, questin, sulochrin, and demethylasterric acid. The study also presents the collection of mass spectra that can serve as a resource for future experiments. The growth in a salt-rich environment turned out to be strongly inhibitory for secondary metabolism and the formation of dense and compact pellets was observed. Generally, the addition of inulin, reducing the oxygen supply, and increasing the content of nitrogen source
\end{abstract}

Electronic supplementary material The online version of this article (doi:10.1007/s00253-015-7157-1) contains supplementary material, which is available to authorized users.

Tomasz Boruta

tomaszboruta85@gmail.com

1 Faculty of Process and Environmental Engineering, Department of Bioprocess Engineering, Lodz University of Technology, ul. Wolczanska 213, 90-924 Lodz, Poland did not enhance the production of examined molecules. The most successful strategy involved the addition of rapeseed oil to the chlorine-deficient medium. Under these conditions, the highest levels of butyrolactone I, asterric acid, and mevinolinic acid were achieved and the presence of desmethylsulochrin and (+)-bisdechlorogeodin was detected in the broth. The constant and relatively high aeration rate in the idiophase was shown to be beneficial for terrein and (+)geodin biosynthesis.

Keywords Aspergillus terreus · Secondary metabolites · Lovastatin $\cdot(+)$-Geodin

\section{Introduction}

Fungi are well-known for their ability to biosynthesize a vast array of low molecular weight molecules with sophisticated structures and various biological functions. These compounds, traditionally referred to as secondary metabolites, are not necessary for the operation of energetic and growth systems of the cell, yet their formation has been established in the course of evolution as being advantageous for the producing organism (Demain and Fang 2000). The examples of fungal secondary metabolites are polyketides, non-ribosomal peptides, and terpenes (Keller et al. 2005). Importantly, the secondary metabolic machineries of fungi are considered to be rich sources of potential drug candidates and other useful substances. The widely recognized examples of industrially and medically relevant metabolites of fungal origin are penicillin, a beta-lactam antibiotic produced by Penicillium chrysogenum, and lovastatin, a cholesterol-lowering drug secreted by Aspergillus terreus (Alberts et al. 1980; Brakhage 1998; Tobert 2003). 
The cascades of cellular events leading to the biosynthesis of secondary metabolites are controlled at multiple levels (Brakhage 2013). As opposed to primary metabolic pathways, the activity of secondary pathways is typically observed only under specific conditions. The evolutionarily shaped set of environmental factors and complex molecular mechanisms associated with the activation of biosynthetic genes is generally very difficult or even impossible to fully elucidate. The genes may remain silent under the applied cultivation strategy due to a lack of required stimuli and, as a result, the corresponding molecules are not produced. To address this issue, the methods of genome mining have been devised to trigger the formation of the respective secondary metabolites by using the tools of genetic engineering (Bok et al. 2015; Bergmann et al. 2007; Brakhage and Schroeckh 2011; Guo and Wang 2014; Ochi and Hosaka 2013). An alternative strategy involves the examination of diverse cultivation conditions and media compositions in order to uncover the metabolic repertoire of strains under investigation (Bode et al. 2002). The rationale behind this bioprocess-oriented approach is that the resemblance of natural stimuli leading to biosynthesis of secondary metabolites can, in principle, be achieved through extensive testing of various growth conditions in the laboratory setting. The typically considered process-related variables include carbon and nitrogen sources, $\mathrm{pH}$, aeration, temperature, and the concentration of nutrients. The objective of the underlying procedures is to mimic the environmental conditions and signals that elicit the molecular response associated with awakening of the corresponding genes. The regulation of fungal secondary metabolism was shown to be integrated with stress response mechanisms (Duran et al. 2010; Roze et al. 2011; Yin et al. 2013). Therefore, subjecting the target strain to oxidative, osmotic, and other forms of stress may reveal the previously unknown part of the metabolome. Not only do such experiments open the door for the exploration of fungal metabolic landscapes but they also allow for the identification of key process-related factors that stimulate biosynthetic pathways. Moreover, they provide the preliminary data to facilitate further bioprocess development and optimizations efforts oriented towards reaching high titers, productivities, and yields of the desired molecules. By investigating the metabolic profiles under diverse conditions, one may not only search for the conditions that maximize the synthesis of the target compounds but, simultaneously, investigate the factors that reduce or eliminate the formation of unwanted by-products. Monitoring of the broad spectrum of metabolites during the cultivation process leads to the more complete picture of the biosynthetic capabilities of the employed strains (Sarkar et al. 2012).

Aspergillus terreus is a textbook example of an industrially exploited filamentous fungus. Its major metabolite lovastatin, also known as mevinolin, is applied in cholesterol lowering treatments. This species has been a subject of many experimental works devoted to the natural products and the results clearly indicate that its biosynthetic potential reaches far beyond the formation of lovastatin. The search in the Antibase 2014 database of secondary metabolites with the query "Aspergillus terreus" yields 165 chemical structures of compounds that have been reported for this fungus throughout the years of research. Importantly, this relatively high number corresponds to the overall number of investigated strains and isolates, encompassing the ones isolated from soil, marine environments, and plant material. Knowing the longestablished industrial status of $A$. terreus, it is justified to examine the true metabolic capabilities of a single, biotechnologically relevant strain and monitor its chemical catalogue in the context of the diversified growth media and cultivation conditions. A well-suited candidate for this purpose is A. terreus ATCC 20542, a wild-type parent strain of industrial lovastatin-overproducing mutants (Alberts et al. 1980; Monaghan et al. 1980). Its secondary metabolic repertoire has been a subject of previous qualitative investigations conducted for the cultures propagated on the solid media (Samson et al. 2011) and in shake flasks (Boruta and Bizukojc 2014). Vinci et al. (1991) described a number of metabolic byproducts detected during the industrial-scale production of lovastatin, including asterric acid and sulochrin; however, the study was conducted with the use of mutant strains derived from A. terreus ATCC 20542 and it was focused on the reduction of co-metabolites formation. The comprehensive bioreactor-based analysis of secondary metabolic spectrum of the wild-type parent strain has not been reported previously.

This paper addresses the media- and conditions-dependent induction of secondary metabolites biosynthesis by $A$. terreus ATCC 20542 in a 5-1 stirred tank bioreactor. The presented qualitative and quantitative analysis considered the bioprocess-related factors associated with the induction of biosynthetic pathways in A. terreus that can be further tested for other fungal systems. The mini-database of mass spectra and fragmentation patterns of encountered molecules is also provided, the resource that may be used in the future analytical studies on A. terreus metabolism.

\section{Materials and methods}

\section{Strain}

Aspergillus terreus ATCC 20542 was used throughout the study.

\section{Media and cultivation conditions}

The composition of the solid agar medium used for the production of conidia was as follows: malt extract $\left(20 \mathrm{~g} \mathrm{l}^{-1}\right)$, casein peptone $\left(5 \mathrm{~g}^{-1}\right)$, agar $\left(30 \mathrm{~g}^{-1}\right)$. 
The growth media contained the following: lactose, $20 \mathrm{~g} \mathrm{l}^{-1}\left(10 \mathrm{~g} \mathrm{l}^{-1}\right.$ in the preculture); $\mathrm{KH}_{2} \mathrm{PO}_{4}, 1.51 \mathrm{~g} \mathrm{l}^{-1}$; yeast extract (BD, USA), $2 \mathrm{gl}^{-1}$ in all bioreactor runs except $\mathrm{R} 3$ and $\mathrm{R} 4,4 \mathrm{~g} \mathrm{l}^{-1}$ in run R3, $0.5 \mathrm{~g} \mathrm{l}^{-1}$ in run $\mathrm{R} 4,8 \mathrm{~g} \mathrm{l}^{-1}$ in the preculture; $\mathrm{MgSO}_{4} \cdot 7 \mathrm{H}_{2} \mathrm{O}, 0.52 \mathrm{~g} \mathrm{l}^{-1} ; \mathrm{ZnSO}_{4} \cdot 7 \mathrm{H}_{2} \mathrm{O}$, $1 \mathrm{mg} \mathrm{l}^{-1} ; \mathrm{Fe}(\mathrm{NO})_{3} \cdot 9 \mathrm{H}_{2} \mathrm{O}, 2 \mathrm{mg} \mathrm{l}^{-1}$; biotin, $0.04 \mathrm{mg} \mathrm{l}^{-1}$. One milliliter of the following solution was added per liter of medium: $\mathrm{H}_{3} \mathrm{BO}_{3}, 65 \mathrm{mg} \mathrm{l}^{-1} ; \mathrm{MnSO}_{4} \cdot 1 \mathrm{H}_{2} \mathrm{O}, 43 \mathrm{mg} \mathrm{l}{ }^{-1} ; \mathrm{CuSO}_{4}$. $5 \mathrm{H}_{2} \mathrm{O}, 250 \mathrm{mg} \mathrm{l}^{-1} ; \mathrm{Na}_{2} \mathrm{MoO}_{4} \cdot 2 \mathrm{H}_{2} \mathrm{O}, 50 \mathrm{mg} \mathrm{l}^{-1}$. Inulin from chicory (Sigma-Aldrich, USA) at the concentration of $5 \mathrm{~g} \mathrm{l}^{-1}$ served as an additional carbon source in the run R2. With the exception of the runs R1, R7 and the preculture for the run R7, the media contained $\mathrm{NaCl}$ at the concentration of $0.4 \mathrm{~g} \mathrm{l}^{-1}$. In the run $\mathrm{R} 1$, the concentration of $\mathrm{NaCl}$ was equal to $150 \mathrm{~g} \mathrm{l}^{-1}$. In the run $\mathrm{R} 7$, and the corresponding preculture $\mathrm{Na}_{2} \mathrm{SO}_{4}$ $\left(0.486 \mathrm{~g} \mathrm{l}^{-1}\right)$ was used as a source of sodium instead of $\mathrm{NaCl}$.

In the runs R1, R2, R3, and R4, the silicone oil Antifoam A (Sigma-Aldrich, USA) was employed as a foam suppresser, while in the runs R5, R6, R7, and R8 cold-filtered rapeseed oil (ZT Kruszwica SA, Poland) was used (10 ml per liter of medium) as an anti-foam agent and an additional source of carbon. Five milliliters of rapeseed oil per liter of medium was added prior to inoculation and the remaining volume was added during the initial $24 \mathrm{~h}$ of cultivation.

The $\mathrm{pH}$ value of culture media was adjusted to 6.5 by using $\mathrm{NaOH}$. The media in the bioreactor were autoclaved at $121^{\circ} \mathrm{C}$ for $90 \mathrm{~min}$.

Induction of sporulation was achieved by propagating the fungus for 10 days on malt agar slants. The conidia were transferred to shake flasks by washing with the medium to reach approximately $10^{9}$ conidia per liter of the preculture. Three hundred milliliters of the preculture was prepared by cultivating the fungus for $24 \mathrm{~h}$ in two shake flasks (total volume $500 \mathrm{ml}$, working volume $150 \mathrm{ml}$ ). The rotary shaker speed was set to the constant value of $110 \mathrm{rpm}$ and the temperature was maintained at $30{ }^{\circ} \mathrm{C}$. The inoculation with the 24-h preculture resulted in the initial biomass concentration in the bioreactor between 0.1 and $0.15 \mathrm{~g} \mathrm{l}^{-1}$.

Experimental runs were performed for $168 \mathrm{~h}$ at $30^{\circ} \mathrm{C}$ in a stirred tank bioreactor BIOSTAT ${ }^{\circledR}$ B Plus (Sartorius, Germany) with the working volume of 5.41 . In all runs except $\mathrm{R} 5$ and $\mathrm{R} 8$, the initial value of $v v m$ (ratio of air flow rate and bioreactor volume) was set to $0.281_{\text {air }} 1^{-1} \mathrm{~min}^{-1}$, the initial rotary speed of the impeller was equal to $200 \mathrm{rpm}$ (rotations per minute), and the dissolved oxygen saturation level was controlled at the level of $20 \%$ by adjusting the air flow rate and impeller speed. In the run R5, the oxygen saturation level was not controlled, the agitation speed was maintained at $200 \mathrm{rpm}$, and the $v v m$ value was kept at $0.281_{\text {air }} r^{-1} \mathrm{~min}^{-1}$ except the period between 32 and $47 \mathrm{~h}$, when the intentional shutdown of aeration took place and the $v v m$ value was equal to 0 . In the run R8, there was no control of oxygen saturation level, the impeller speed was constant at $240 \mathrm{rpm}$, and the $v v m$ was constant at $0.751_{\text {air }} 1^{-1} \min ^{-1}$.

\section{Analytical methods}

Secondary metabolites were analyzed by using the ultra-high performance liquid chromatography (UPLC ${ }^{\circledR}$ Acquity)-mass spectrometry (SYNAPT G2) system (Waters, USA). The chromatographic procedure was executed as previously described (Bizukojc et al. 2012). The mass spectrometry analysis was conducted both in positive and negative electrospray ionization modes. The following parameters were applied: the temperature of the source was set to $120^{\circ} \mathrm{C}$; desolvation temperature was $200{ }^{\circ} \mathrm{C}$ in ESI+ mode and $400{ }^{\circ} \mathrm{C}$ in ESI- mode; voltage was $3 \mathrm{kV}$ for the capillary, $40 \mathrm{~V}$ for the sampling cone, and $4 \mathrm{~V}$ for the extraction cone; flow rate of desolvation gas (nitrogen) was equal to $500 \mathrm{lh}^{-1}$ in ESI+ and $1000 \mathrm{l} \mathrm{h}^{-1}$ in ESI- mode. The absorbance spectra generated by using the photodiode array (PDA) detector were scrutinized in concert with the chromatograms and mass spectra in the process of metabolite detection and identification. The database of natural products AntiBase 2014: The Natural Compound Identifier (Laatsch 2014) was consulted in the course of the qualitative analysis of molecules.

Quantitative analyses of mevinolinic acid, (+)-geodin, and terrein were carried out by means of UPLC ${ }^{\circledR}$ Acquity (Waters, USA) with the photodiode array detector at $\lambda=238 \mathrm{~nm}$ (for mevinolinic acid) and $\lambda=280 \mathrm{~nm}$ (for (+)-geodin and terrein). Asterric acid and butyrolactone I were assayed by the LC-MS/ MS method implemented in TargetLynx ${ }^{\mathrm{TM}}$ (Waters, USA) in a positive and negative electrospray ionization mode, respectively. The quantification traces for asterric acid and butyrolactone I were defined as $m / z=331.086$ and $m / z=423.146$, respectively. The calibration curves for the quantitative assays were developed by using standard solutions prepared from commercially available metabolites. The standard solution of mevinolinic acid was formulated by using the method presented in earlier study Casas López et al. (2003). The standard solution of (+)-geodin was prepared by dissolving (+)-geodin (Santa Cruz Biotechnology, USA) in a solution of acetonitrile and water $(1: 1 v / v)$. The standard solutions of asterric acid (Enzo Life Sciences, USA) and butyrolactone I (Enzo Life Sciences, USA) were prepared in acetonitrile, while terrein (SigmaAldrich, USA) was dissolved in water. The reference samples of questin and sulochrin were kindly provided by Prof. Dr. Isao Fujii, Iwate Medical University, Japan.

Image analysis regarding fungal morphology was performed as previously described (Gonciarz and Bizukojc 2014).

\section{Molecular formulae of secondary metabolites, $m / z$ of pseudomolecular ion peaks and experimental errors}

(+)-Bisdechlorogeodin $\left(\mathrm{C}_{17} \mathrm{H}_{14} \mathrm{O}_{7}\right.$; calculated $m / z[\mathrm{M}+\mathrm{H}]^{+}=$ 331.0812; experimental $\mathrm{m} / \mathrm{z}[\mathrm{M}+\mathrm{H}]^{+}=331.0857$; error $\Delta m /$ 
$z=+0.0045)$; (+)-erdin $\left(\mathrm{C}_{16} \mathrm{H}_{10} \mathrm{Cl}_{2} \mathrm{O}_{7}\right.$; calc. $m / z[\mathrm{M}+\mathrm{H}]^{+}=$ 384.9876; exper. $\left.m / z[\mathrm{M}+\mathrm{H}]^{+}=384.9872 ; \Delta m / z=-0.0004\right)$; (+)-geodin $\left(\mathrm{C}_{17} \mathrm{H}_{12} \mathrm{Cl}_{2} \mathrm{O}_{7}\right.$; calc. $m / z[\mathrm{M}+\mathrm{H}]^{+}=399.0033$; exper. $\left.m / z[\mathrm{M}+\mathrm{H}]^{+}=399.0057 ; \Delta m / z=+0.0024\right) ; 3 \alpha$-hydroxy-3,5-dihydromonacolin $\mathrm{L}$ acid $\left(\mathrm{C}_{19} \mathrm{H}_{32} \mathrm{O}_{5}\right.$; calc. $\mathrm{m} / z$ $[\mathrm{M}-\mathrm{H}]^{-}=339.2177$; exper. $m / z[\mathrm{M}-\mathrm{H}]^{-}=339.2166 ; \Delta m / z=$ $-0.0011)$; aspulvinone $\mathrm{E}\left(\mathrm{C}_{17} \mathrm{H}_{12} \mathrm{O}_{5}\right.$; calc. $m / z[\mathrm{M}-\mathrm{H}]^{-}=$ 295.0612; exper. $\left.m / z[\mathrm{M}-\mathrm{H}]^{-}=295.0606 ; \Delta m / z=-0.0006\right)$; asterric acid $\left(\mathrm{C}_{17} \mathrm{H}_{16} \mathrm{O}_{8}\right.$; calc. $m / z[\mathrm{M}+\mathrm{H}]^{+}=349.0918$; exper. $m / z[\mathrm{M}+\mathrm{H}]^{+}=349.0882 ; \Delta m / z=-0.0036$ ); butyrolactone $\mathrm{I}\left(\mathrm{C}_{24} \mathrm{H}_{24} \mathrm{O}_{7}\right.$; calc. $m / z[\mathrm{M}-\mathrm{H}]^{-}=423.1449$; exper. $\left.m / z[\mathrm{M}-\mathrm{H}]^{-}=423.1462 ; \Delta m / z=+0.0013\right)$; demethylasterric acid $\left(\mathrm{C}_{16} \mathrm{H}_{14} \mathrm{O}_{8}\right.$; calc. $m / z[\mathrm{M}+\mathrm{H}]^{+}=$ 335.0761 ; exper. $m / z[\mathrm{M}+\mathrm{H}]^{+}=335.0797 ; \Delta m / z=+$ 0.0036); desmethylsulochrin $\left(\mathrm{C}_{16} \mathrm{H}_{14} \mathrm{O}_{7}\right.$; calc. $m / z[\mathrm{M}+$ $\mathrm{H}]^{+}=319.0812$; exper. $m / z[\mathrm{M}+\mathrm{H}]^{+}=319.0835 ; \Delta m / z=+$ $0.0023)$; dihydroisoflavipucine $\left(\mathrm{C}_{12} \mathrm{H}_{17} \mathrm{NO}_{4}\right.$; calc. $m / z[\mathrm{M}+$ $\mathrm{H}]^{+}=240.1230$; exper. $m / z[\mathrm{M}+\mathrm{H}]^{+}=240.1268 ; \Delta m / z=+$ 0.0038); 4a,5-dihydromevinolinic acid $\left(\mathrm{C}_{24} \mathrm{H}_{40} \mathrm{O}_{6}\right.$; calc. $\mathrm{m} / \mathrm{z}$ $[\mathrm{M}+\mathrm{H}]^{+}=425.2898$; exper. $m / z[\mathrm{M}+\mathrm{H}]^{+}=425.2870 ; \Delta m /$ $z=-0.0028)$; mevinolinic acid $\left(\mathrm{C}_{24} \mathrm{H}_{38} \mathrm{O}_{6}\right.$; calc. $m / z[\mathrm{M}+$ $\mathrm{H}]^{+}=423.2741$; exper. $m / z[\mathrm{M}+\mathrm{H}]^{+}=423.2716 ; \Delta m / z=$ $-0.0025)$; questin $\left(\mathrm{C}_{16} \mathrm{H}_{12} \mathrm{O}_{5}\right.$; calc. $m / z[\mathrm{M}+\mathrm{H}]^{+}=$ 285.0758 ; exper. $m / z[\mathrm{M}+\mathrm{H}]^{+}=285.0770 ; \Delta m / z=+$ $0.0012)$; sulochrin $\left(\mathrm{C}_{17} \mathrm{H}_{16} \mathrm{O}_{7}\right.$; calc. $m / z[\mathrm{M}+\mathrm{H}]^{+}=$ 333.0969; exper. $m / z[\mathrm{M}+\mathrm{H}]^{+}=333.0997 ; \Delta m / z=+$ 0.0028); terrein $\left(\mathrm{C}_{8} \mathrm{H}_{10} \mathrm{O}_{3}\right.$; calc. $m / z[\mathrm{M}+\mathrm{H}]^{+}=155.0703$; exper. $m / z[\mathrm{M}+\mathrm{H}]^{+}=155.0705 ; \Delta m / z=+0.0002$ )

\section{Results}

Three general approaches, employed separately or simultaneously, were tested for their capability to elicit biosynthesis of secondary metabolites in the bioreactor cultures of A. terreus ATCC 20542. The first strategy was to activate cellular stress response that might lead to the stimulation of biosynthetic metabolic routes. This was attempted by establishing high salt conditions, performing temporal shutdown of air flow in the bioreactor, using various aeration strategies, and minimalizing the level of chlorine in the medium. The second method involved the supplementation with an additional carbon source, namely inulin or rapeseed oil. The third approach relied on changing the concentration of nitrogen source in the medium. The scheme of the performed experimental runs is presented in Fig. 1 to illustrate the differences between the investigated cultures.

\section{Identification of secondary metabolites}

Altogether, 15 secondary metabolites were identified in the cultivation broths. The metabolites were analyzed by the combined approach involving three methods. The first step was to

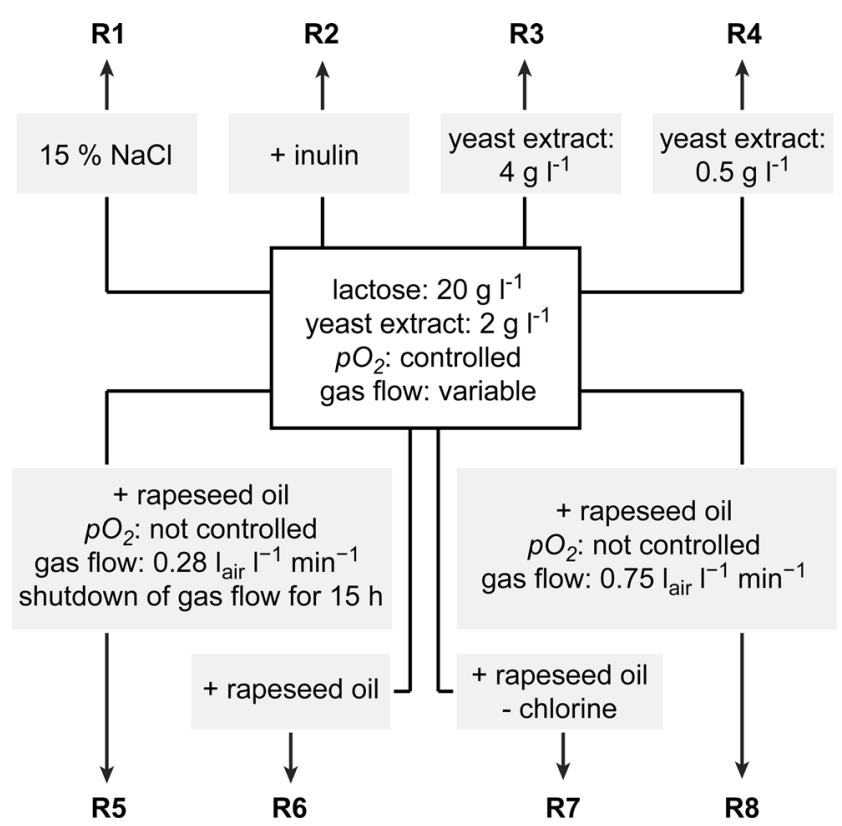

Fig. 1 Scheme of experimental runs. Each run involved a number of modifications with respect to the set of conditions presented in the box. Run R1 involved the highly saline environment of $15 \%(w / v)$ sodium chloride; inulin was added to the R2 medium; two different concentration values of yeast extract were tested in R3 and R4; rapeseed oil was supplemented in the runs R5, R6, R7, and R8; distinctive aeration strategies were applied in the runs R5 and R8; the reduction of chlorine content in the R7 run was achieved by eliminating sodium chloride from the medium

analyze the mass and fragmentation of molecules by mass spectrometry, which led to the determination of the accurate mass values of metabolites and their fragments. The second step was based on retention time analysis. The third step was based on absorbance measurements at different wavelengths and analysis of UV spectra with the use of the photodiode array detector (PDA) for all metabolites. The results at each step where compared with the data obtained for standards or, whenever they were not available, with literature data. The metabolites detected in the study were all reported previously but their simultaneous production was never a subject of a comprehensive study involving bioreactor cultivation. The presence of mevinolinic acid, (+)-geodin, terrein, asterric acid, butyrolactone I, questin, and sulochrin was confirmed by considering the mass spectra, elution times, and absorbance data obtained for the available standard solutions. Recognition of 4a,5-dihydromevinolinic acid, $3 \alpha$-hydroxy-3,5dihydromonacolin $\mathrm{L}$ acid, (+)-erdin, (+)-bisdechlorogeodin, demethylasterric acid, aspulvinone $\mathrm{E}$, dihydroisoflavipucine, and desmethylsulochrin was based on the thorough analysis of spectral data and its comparison with the available literature records. The observed fragmentation patterns of the detected metabolites with the suggested masses are presented in Table 1, while the collection of mass spectra is provided in the Supplementary material (Figs. S1-S15). For the majority of examined molecules, a strong and distinctive signal was 
Table 1 Fragmentation patterns observed in mass spectra of secondary metabolites detected in bioreactor cultures of A. terreus ATCC 20542

Name of metabolite $\quad$ Experimental $\mathrm{m} / \mathrm{z}$ values of identified pseudo-molecular ions and fragmentation ions with the corresponding losses

\begin{tabular}{|c|c|c|}
\hline & \\
\hline & ESI+ mode & ESI- mode \\
\hline$(+)$-Bisdechlorogeodin & $\begin{array}{l}\text { 331.0857, [M+H }]^{+} ; 299.0583,\left[\mathrm{M}-\mathrm{CH}_{3} \mathrm{OH}+\mathrm{H}\right]^{+} ; 287.0940 \\
\quad\left[\mathrm{M}-\mathrm{CO}_{2}+\mathrm{H}\right]^{+}\end{array}$ & $\begin{array}{l}\text { 329.0677, [M-H }]^{-} ; 245.0809,[\mathrm{M}-3 \mathrm{CO}-\mathrm{H}]^{-} ; \\
\quad 167.0350,\left[\mathrm{M}-\mathrm{C}_{9} \mathrm{H}_{6} \mathrm{O}_{3}-\mathrm{H}\right]^{-}\end{array}$ \\
\hline$(+)$-Erdin & $\begin{array}{l}\text { 384.9872, [M+H }]^{+} ; 340.9987,\left[\mathrm{M}-\mathrm{CO}_{2}+\mathrm{H}\right]^{+} ; 325.9790 \\
\quad\left[\mathrm{M}+\mathrm{H}-\mathrm{C}_{2} \mathrm{H}_{3} \mathrm{O}_{2}\right]^{+}\end{array}$ & $382.9689,[\mathrm{M}-\mathrm{H}]^{-} ; 338.9831,\left[\mathrm{M}-\mathrm{CO}_{2}-\mathrm{H}\right]^{-}$ \\
\hline$(+)$-Geodin & $\begin{array}{l}399.0057,[\mathrm{M}+\mathrm{H}]^{+} ; 366.9813,\left[\mathrm{M}-\mathrm{CH}_{3} \mathrm{OH}+\mathrm{H}\right]^{+} ; 355.0138 \\
\quad\left[\mathrm{M}-\mathrm{CO}_{2}+\mathrm{H}\right]^{+} ; 339.9911,\left[\mathrm{M}+\mathrm{H}-\mathrm{COOCH}_{3}\right]^{+}\end{array}$ & $396.9890,[\mathrm{M}-\mathrm{H}]^{-}$ \\
\hline $\begin{array}{l}\text { 3 } \alpha \text {-Hydroxy-3,5- } \\
\quad \text { dihydromonacolin L acid }\end{array}$ & $\begin{array}{l}\left.\text { 323.2245, [M- } \mathrm{H}_{2} \mathrm{O}+\mathrm{H}\right]^{+} ; 305.2083,\left[\mathrm{M}-2 \mathrm{H}_{2} \mathrm{O}+\mathrm{H}\right]^{+} \\
\quad 287.1976,\left[\mathrm{M}-3 \mathrm{H}_{2} \mathrm{O}+\mathrm{H}\right]^{+} ; 681.4574,[2 \mathrm{M}+\mathrm{H}]^{+} ; \\
\quad 645.4343,\left[2 \mathrm{M}-2 \mathrm{H}_{2} \mathrm{O}+\mathrm{H}\right]^{+} ; 627.4283,\left[2 \mathrm{M}-3 \mathrm{H}_{2} \mathrm{O}+\mathrm{H}\right]^{+}\end{array}$ & $339.2166,[\mathrm{M}-\mathrm{H}]^{-}$ \\
\hline Aspulvinone $\mathrm{E}$ & - & 295.0606, [M-H] $]^{-}$ \\
\hline Asterric acid & $\begin{array}{r}349.0882,[\mathrm{M}+\mathrm{H}]^{+} ; 331.0857,\left[\mathrm{M}-\mathrm{H}_{2} \mathrm{O}+\mathrm{H}\right]^{+} ; 299.0583 \\
{\left[\mathrm{M}-\mathrm{H}_{2} \mathrm{O}-\mathrm{CH}_{3} \mathrm{OH}+\mathrm{H}\right]^{+} ; 287.0940,\left[\mathrm{M}-\mathrm{H}_{2} \mathrm{O}-\mathrm{CO}_{2}+\mathrm{H}\right]^{+}}\end{array}$ & $\begin{array}{l}\text { 347.0801, [M-H] } ; 303.0897,\left[\mathrm{M}-\mathrm{CO}_{2}-\mathrm{H}\right]^{-} \\
\quad 271.0583,\left[\mathrm{M}-\mathrm{CO}_{2}-\mathrm{CH}_{3} \mathrm{OH}-\mathrm{H}\right]^{-}\end{array}$ \\
\hline Butyrolactone I & - & $\begin{array}{l}\text { 423.1462, [M-H] }]^{-} ; 379.1541,\left[\mathrm{M}-\mathrm{CO}_{2}-\mathrm{H}\right]^{-} \\
\text {364.1277, }\end{array}$ \\
\hline Demethylasterric acid & $\begin{array}{l}335.0797,[\mathrm{M}+\mathrm{H}]^{+} ; 317.0658,\left[\mathrm{M}-\mathrm{H}_{2} \mathrm{O}+\mathrm{H}\right]^{+} ; 299.0583 \\
\quad\left[\mathrm{M}-2 \mathrm{H}_{2} \mathrm{O}+\mathrm{H}\right]^{+} ; 273.0737,\left[\mathrm{M}-\mathrm{H}_{2} \mathrm{O}-\mathrm{CO}_{2}+\mathrm{H}\right]^{+}\end{array}$ & $\begin{array}{l}333.0609,[\mathrm{M}-\mathrm{H}]^{-} ; 289.0686,\left[\mathrm{M}-\mathrm{CO}_{2}-\mathrm{H}\right]^{-} \\
\quad 245.0809,\left[\mathrm{M}-2 \mathrm{CO}_{2}-\mathrm{H}\right]^{-} ; 167.0350 \\
\quad\left[\mathrm{M}-\mathrm{C}_{8} \mathrm{H}_{6} \mathrm{O}_{4}-\mathrm{H}\right]^{-}\end{array}$ \\
\hline Desmethylsulochrin & $\begin{array}{l}\text { 319.0835, }[\mathrm{M}+\mathrm{H}]^{+} ; 301.0710,\left[\mathrm{M}-\mathrm{H}_{2} \mathrm{O}+\mathrm{H}\right]^{+} ; 195.0269 \\
\quad\left[\mathrm{M}-\mathrm{C}_{7} \mathrm{H}_{8} \mathrm{O}_{2}+\mathrm{H}\right]^{+}\end{array}$ & $\begin{array}{l}317.0691,[\mathrm{M}-\mathrm{H}]^{-} ; 285.0392,\left[\mathrm{M}-\mathrm{CH}_{3} \mathrm{OH}-\mathrm{H}\right]^{-} \\
241.0459,\left[\mathrm{M}-\mathrm{CH}_{3} \mathrm{OH}-\mathrm{CO}_{2}-\mathrm{H}\right]^{-} ; 193.0154 \\
\quad\left[\mathrm{M}-\mathrm{C}_{7} \mathrm{H}_{8} \mathrm{O}_{2}-\mathrm{H}\right]^{-}\end{array}$ \\
\hline Dihydroisoflavipucine & $\begin{array}{l}\text { 240.1268, [M+H }+\mathrm{H}]^{+} ; 142.0508,\left[\mathrm{M}-\mathrm{C}_{6} \mathrm{H}_{10} \mathrm{O}+\mathrm{H}\right]^{+}, 479.2446 \\
{[2 \mathrm{M}+\mathrm{H}]^{+}}\end{array}$ & - \\
\hline $\begin{array}{l}\text { 4a,5-Dihydromevinolinic } \\
\text { acid }\end{array}$ & $\begin{array}{l}425.2870,[\mathrm{M}+\mathrm{H}]^{+} ; 407.2763,\left[\mathrm{M}-\mathrm{H}_{2} \mathrm{O}+\mathrm{H}\right]^{+} ; 305.2159 \\
{\left[\mathrm{M}-\mathrm{H}_{2} \mathrm{O}-\mathrm{C}_{5} \mathrm{H}_{10} \mathrm{O}_{2}+\mathrm{H}^{+} ; 287.2050,\left[\mathrm{M}-2 \mathrm{H}_{2} \mathrm{O}-\mathrm{C}_{5} \mathrm{H}_{10} \mathrm{O}_{2}+\mathrm{H}\right]^{+} ;\right.} \\
269.1897,\left[\mathrm{M}-3 \mathrm{H}_{2} \mathrm{O}-\mathrm{C}_{5} \mathrm{H}_{10} \mathrm{O}_{2}+\mathrm{H}\right]^{+} ; 245.1892,\left[\mathrm{M}-\mathrm{H}_{2} \mathrm{O}-\right. \\
\left.\mathrm{C}_{5} \mathrm{H}_{10} \mathrm{O}_{2}-\mathrm{CH} \mathrm{HOOH}_{3} \mathrm{COOH}\right]^{+} ; 227.1812,\left[\mathrm{M}-2 \mathrm{H}_{2} \mathrm{O}-\mathrm{C}_{5} \mathrm{H}_{10} \mathrm{O}_{2^{-}}\right. \\
\left.\mathrm{CH}_{3} \mathrm{COOH}+\mathrm{H}\right]^{+} ; 201.1625,\left[\mathrm{M}-\mathrm{H}_{2} \mathrm{O}-\mathrm{C}_{5} \mathrm{H}_{10} \mathrm{O}_{2}-\mathrm{CH}_{3} \mathrm{COOH}-\right. \\
\left.\mathrm{C}_{2} \mathrm{H}_{4} \mathrm{O}+\mathrm{H}\right]^{+} ; 203.1810,\left[\mathrm{M}-\mathrm{H}_{2} \mathrm{O}-\mathrm{C}_{5} \mathrm{H}_{10} \mathrm{O}_{2}-\mathrm{C}_{4} \mathrm{H}_{6} \mathrm{O}_{3}+\mathrm{H}\right]^{+}\end{array}$ & 423.2722, $[\mathrm{M}-\mathrm{H}]^{-}$ \\
\hline Mevinolinic acid & $\begin{array}{l}\text { 423.2716, [M+H] }]^{+} ; 405.2600,\left[\mathrm{M}-\mathrm{H}_{2} \mathrm{O}+\mathrm{H}\right]^{+} ; 303.1969 \\
{\left[\mathrm{M}-\mathrm{H}_{2} \mathrm{O}-\mathrm{C}_{5} \mathrm{H}_{10} \mathrm{O}_{2}+\mathrm{H}\right]^{+} ; 285.1876,\left[\mathrm{M}-2 \mathrm{H}_{2} \mathrm{O}-\mathrm{C}_{5} \mathrm{H}_{10} \mathrm{O}_{2}+\mathrm{H}\right]^{+} ;} \\
267.1725,\left[\mathrm{M}-3 \mathrm{H}_{2} \mathrm{O}-\mathrm{C}_{5} \mathrm{H}_{10} \mathrm{O}_{2}+\mathrm{H}\right]^{+} ; 243.1756,\left[\mathrm{M}-\mathrm{H}_{2} \mathrm{O}-\right. \\
\left.\mathrm{C}_{5} \mathrm{H}_{10} \mathrm{O}_{2}-\mathrm{CH} \mathrm{H}_{3} \mathrm{COOH}+\mathrm{H}\right]^{+} ; 225.1644,\left[\mathrm{M}-2 \mathrm{H}_{2} \mathrm{O}-\mathrm{C}_{5} \mathrm{H}_{10} \mathrm{O}_{2^{-}}\right. \\
\left.\mathrm{CH}_{3} \mathrm{COOH}+\mathrm{H}\right]^{+} ; 199.1478,\left[\mathrm{M}-\mathrm{H}_{2} \mathrm{O}-\mathrm{C}_{5} \mathrm{H}_{10} \mathrm{O}_{2}-\mathrm{CH}_{3} \mathrm{COOH}-\right. \\
\left.\mathrm{C}_{2} \mathrm{H}_{4} \mathrm{O}+\mathrm{H}\right]^{+} ; 201.1625,\left[\mathrm{M}-\mathrm{H}_{2} \mathrm{O}-\mathrm{C}_{5} \mathrm{H}_{10} \mathrm{O}_{2}-\mathrm{C}_{4} \mathrm{H}_{6} \mathrm{O}_{3}+\mathrm{H}\right]^{+}\end{array}$ & 421.2598, [M-H] $]^{-}$ \\
\hline Questin & $285.0770,[\mathrm{M}+\mathrm{H}]^{+}$ & $283.0572,[\mathrm{M}-\mathrm{H}]^{-}$ \\
\hline Sulochrin & $\begin{array}{l}\text { 333.0997, }[\mathrm{M}+\mathrm{H}]^{+} ; 301.0710,\left[\mathrm{M}-\mathrm{CH}_{3} \mathrm{OH}+\mathrm{H}\right]^{+} ; 209.0444 \\
\quad\left[\mathrm{M}-\mathrm{C}_{7} \mathrm{H}_{8} \mathrm{O}_{2}+\mathrm{H}\right]^{+}\end{array}$ & 331.0851, [M-H] $]^{-}$299.0541, [M-CH 3 OH-H] $]^{-}$ \\
\hline Terrein & $\begin{array}{l}\text { 155.0705, }[\mathrm{M}+\mathrm{H}]^{+} ; 137.0610,\left[\mathrm{M}-\mathrm{H}_{2} \mathrm{O}+\mathrm{H}\right]^{+} ; 109.0642 \\
\quad\left[\mathrm{M}-\mathrm{H}_{2} \mathrm{O}-\mathrm{CO}+\mathrm{H}\right]^{+}\end{array}$ & - \\
\hline
\end{tabular}

observed in both positive and negative ionization modes. However, for a limited number of metabolites, the signals of significant intensity were found only in one of the employed ionization modes (Table 1). Under the applied analytical conditions, the fragmentation of mevinolinic acid, 4a,5dihydromevinolinic acid, $3 \alpha$-hydroxy-3,5-dihydromonacolin $\mathrm{L}$ acid, and (+)-geodin could be observed solely when the molecules were subjected to the positive ionization.

The examined mass spectra revealed a fragmentation pattern shared between $(+)$-erdin and $(+)$-geodin, which in fact is a methyl ester of (+)-erdin (Fig. 2). The $(+)$-geodin peaks at $m / z=339.9911,355.0138$, and 399.0057 differed by the $\Delta m / z$ value corresponding to the mass of " $\mathrm{CH}_{2}$ " from the corresponding (+)-erdin peaks at $m / z=325.9790$, 340.9987 , and 384.9872, respectively. The theoretical $\mathrm{m} / \mathrm{z}$ value of " $\mathrm{CH}_{2}$ " group is equal to 14.0157 , which fits well in the presented pattern, if the experimental error is considered. This difference in $\mathrm{m} / \mathrm{z}$ reflected the structural relationship between the two molecules (Fig. 2). The analogous observation was made for two other pairs of detected metabolites. The peaks of asterric acid at $\mathrm{m} / \mathrm{z}=349.0882$, 331.0857 , and 287.0940 had their counterparts in the demethylasterric acid spectrum at $\mathrm{m} / z=335.0797$, 317.0658 , and 273.0737, respectively (Table 1). Finally, the sulochrin peaks at $m / z=333.0997$ and $209.0444 \mathrm{had}$ their corresponding " $-\mathrm{CH}_{2}$ " peaks in the spectrum of 


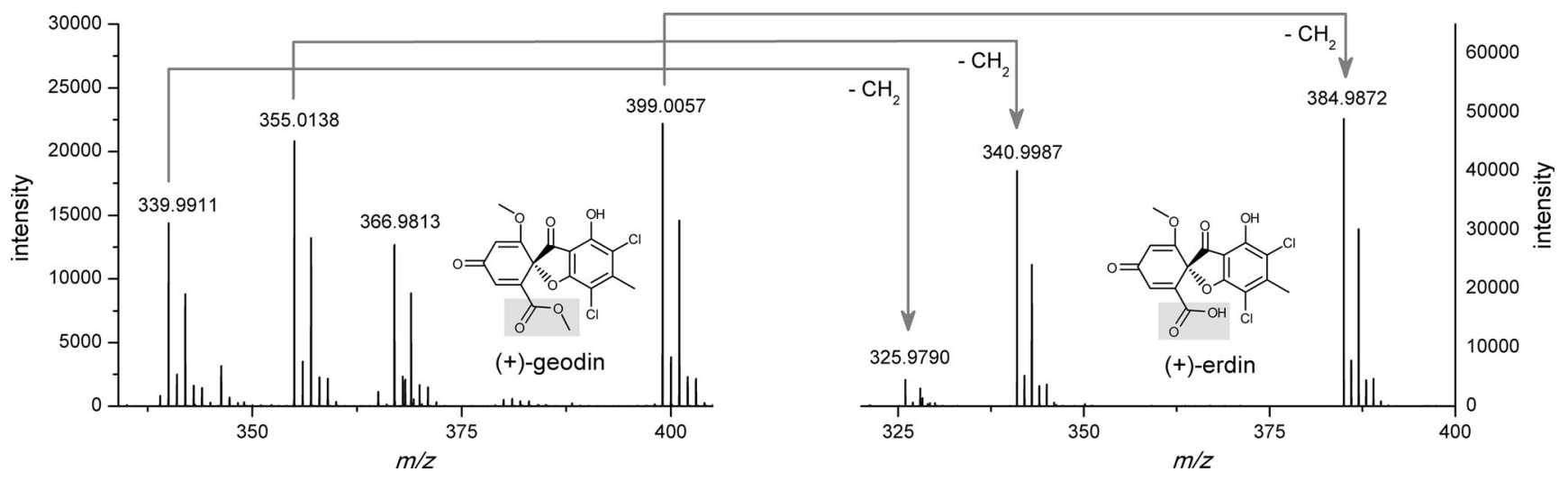

Fig. 2 Scheme of fragmentation pattern observed in mass spectra of $(+)$ geodin and (+)-erdin. The (+)-geodin peaks at $\mathrm{m} / \mathrm{z}=339.9911,355.0138$, and 399.0057 differ by the $\Delta m / z$ value corresponding to the mass of " $\mathrm{CH}_{2}$ " (theoretical $\Delta m / z=14.0157$ ) from the corresponding $(+)$-erdin

peaks at $m / z=325.9790,340.9987$, and 384.9872 , respectively. The relatively small deviations from the theoretical $\Delta m / z$ values are due to the experimental error

desmethylsulochrin (also referred to as demethylsulochrin) at $m / z=319.0835$ and 195.0269, respectively (Table 1).

Another fragmentation pattern was observed to be shared by mevinolinic acid, which is a $\beta$-hydroxy acid form of mevinolin, and 4a,5-dihydromevinolinic acid, a $\beta$-hydroxy acid form of 4a,5-dihydromevinolin (Albers-Schönberg et al. 1981). All the mass peaks of 4a,5-dihydromevinolinic acid had their " $-2 \mathrm{H}$ " counterparts (theoretical $\Delta m / z=2.01565$ ) in the mevinolinic acid spectrum (Table 1). Such behavior was expected, since these two molecules differ structurally only by two hydrogen atoms (Albers-Schönberg et al. 1981).

The mass spectrum of (+)-bisdechlorogeodin including the peaks at $m / z=331.0857,299.0583$, and 287.0940 is in agreement with the positive-ionization data presented by Nielsen and Smedsgaard (2003). The fragment peak at $\mathrm{m} / \mathrm{z}=142.0508$ observed for dihydroisoflavipucine (Table 1) corresponded well with the peak reported previously at $m / z=142.1$ by Zhou (2012). For aspulvinone E, a yellow compound previously isolated from A. terreus (Seto 1979), the relatively strong absorbance was observed at $400 \mathrm{~nm}$. It agrees well with literature data, since yellow substances absorb light at $400 \mathrm{~nm}$ (Pavia et al. 2015). The UV absorption maxima of mevinolinic acid, 4a,5-dihydromevinolinic acid, questin, asterric acid, demethylasterric acid, sulochrin, (+)-bisdechlorogeodin, terrein, butyrolactone I, dihydroisoflavipucine, $(+)$-erdin, and $(+)$-geodin were in agreement with the previously published data (Albers-Schönberg et al. 1981; Calam et al. 1947; Curtis et al. 1960; Guo et al. 2012; Nielsen and Smedsgaard 2003; Zhou 2012).

\section{Influence of growth media and cultivation conditions on biosynthesis of secondary metabolites}

The production of mevinolinic acid, (+)-geodin, terrein, asterric acid, and butyrolactone I was studied quantitatively by using the calibration curves obtained for standard

solutions. The highest observed concentration of each metabolite with relation to the corresponding run is reported in Fig. 3.

The R7 culture, which involved the addition of rapeseed oil with the simultaneous elimination of $\mathrm{NaCl}$ from the medium, proved to be most successful in terms of stimulating mevinolinic acid (Fig. 3a), asterric acid (Fig. 3d), and butyrolactone I (Fig. 3e) biosynthesis. While rapeseed oil was also supplemented in the runs R5, R6, and R8, the removal of all chlorine except the amount present in yeast extract was the unique characteristics of R7 culture. The inducing effect of the nutritional strategy tested in R7 was particularly evident in the case of butyrolactone I (Fig. 3e). The concentration of this metabolite reached $10.32 \mathrm{mg} \mathrm{l}^{-1}$ in the culture $\mathrm{R} 7$, whereas the second highest value, obtained in the run R8, was equal to $3.32 \mathrm{mg} \mathrm{l}^{-1}$. Similar observations were made for asterric acid. Its concentration in R7 reached $2.96 \mathrm{mg} \mathrm{l}^{-1}$, a value which corresponded to 1.8 -fold increase with respect to the values determined for cultures R8 and R6 (Fig. 3d). The R7 culture promoted asterric acid, butyrolacone I, and mevinolinic acid biosynthesis and resulted in the highest observed concentration in the entire study, namely $106.57 \mathrm{mg} \mathrm{l}^{-1}$ of mevinolinic acid (Fig. 3a). However, the conditions of the R7 run were clearly unfavorable with respect to the formation of (+)-geodin (Fig. 3b).

The R8 culture, which involved the addition of rapeseed oil and constant rate of aeration throughout the run, led to the highest observed concentration of terrein (Fig. 3c) and (+)geodin (Fig. 3b) equal to 9.37 and $77.53 \mathrm{mg} \mathrm{l}^{-1}$, respectively. Even though the medium composition was shared among the cultures R5, R6, and R8, the aeration strategies were different (see Fig. 1). Time series data of R5, R6, and R8 runs was confronted with on-line bioreactor measurements of $\mathrm{pH}$, air flow rate, dissolved oxygen saturation level, impeller speed, and redox potential in order to determine the process-related factors that contributed to inducing terrein and (+)-geodin 


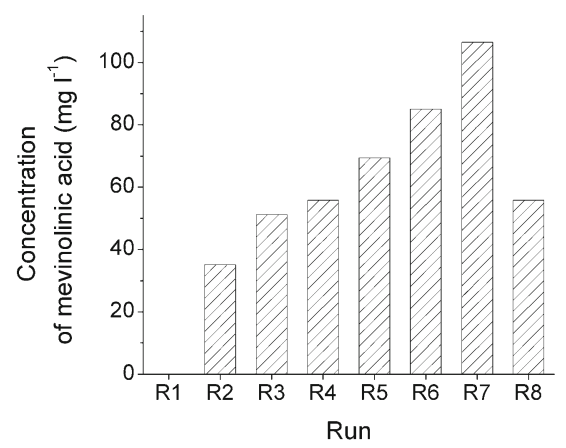

d

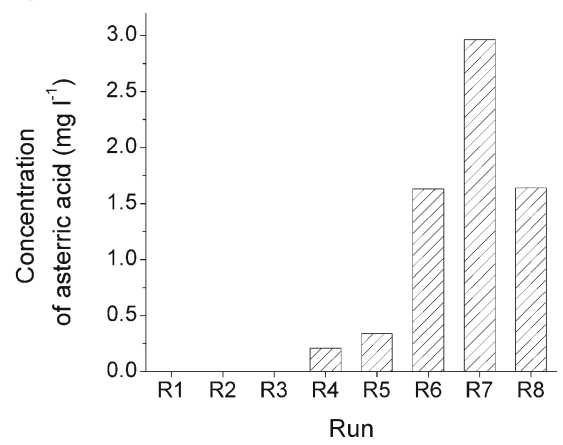

Fig. 3 Results of quantitative analysis of mevinolinic acid (a), (+)geodin (b), terrein (c), asterric acid (d), and butyrolactone I (e). The highest concentration values observed throughout the duration of each run are reported. The formation of mevinolinic acid, asterric acid, and butyrolactone I was favored in the R7 culture, which involved the

formation. The following two correlations were observed. Firstly, the onset of $(+)$-geodin accumulation roughly correlated with the time of $\mathrm{pH}$ inflection point (Fig. 4a). This behavior was observed for all three cultures but there was no observable correlation between the magnitude of the $\mathrm{pH}$ change and the relative $(+)$-geodin titers. A different phenomenon was noticed for terrein (Fig. 4b). The concentration of this metabolite in the R8 culture increased steadily throughout the entire run, while no significant production was observed in the R5 and R6 cultures after $48 \mathrm{~h}$ of cultivation. Notably, it corresponded to the time when the aeration rate of R6 decreased below the rate of R8. Keeping the aeration rate constant at a relatively high level, from the $48 \mathrm{~h}$ until the end of the cultivation, resulted in the increased production of terrein compared to the R5 and R6 cultures (Fig. 4b). All in all, this strategy proved to be more efficient at stimulating biosynthetic routes than shocking the fungus with aeration shutdown and longterm oxygen deficiency in the R5 run, since the concentration of metabolites in the R8 culture turned out to be higher than in oxygen-poor R5 culture, with the single exception of mevinolinic acid (Fig. 3).

The cultures R3 and R4 were characterized by different levels of yeast extract in the medium (Fig. 1). Specifically, the concentration of nitrogen source in the R3 run was eight times higher than in R4. Clearly, under the tested experimental
C

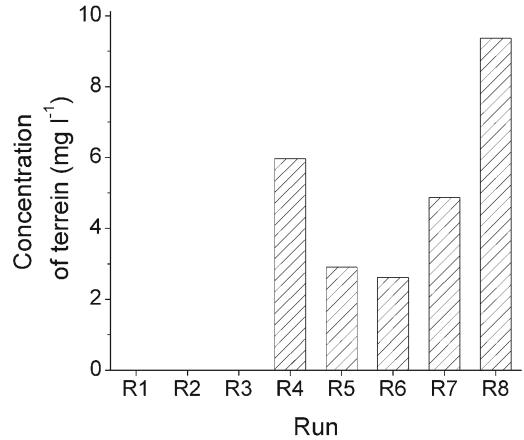

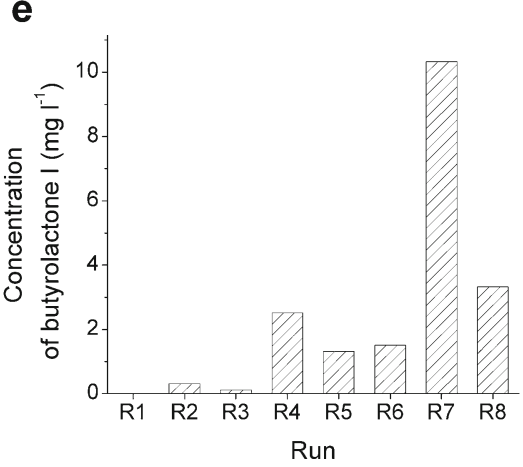

supplementation with rapeseed oil and reduction of chlorine availability. The production of $(+)$-geodin and terrein was enhanced in the R8 culture, which was relatively well aerated during the idiophase. No traces of secondary metabolites were found in the highly saline R1 medium

conditions, the limited nitrogen availability promoted the production of mevinolinic acid, (+)-geodin, terrein, asterric acid, and butyrolactone I (Fig. 3). For all five quantified compounds, the metabolite concentration in the nitrogendeficient R4 culture exceeded the one observed for the nitrogen-richer R3 culture. What is more, the signals corresponding to (+)-geodin, asterric acid, and terrein were not observed at all for the samples originating from the R3 run.

All growth media contained lactose as the main carbon source. The effect of second carbon source addition, namely inulin (R2) and rapeseed oil (R5, R6, R7, and R8), was examined in the context of secondary metabolism induction. The levels of metabolites observed for the oil-containing media were higher than those for the inulin-containing R2 medium (Fig. 3). As in the case of the previously discussed nitrogenrich medium, no significant signals of $(+)$-geodin, asterric ac$\mathrm{id}$, and terrein were detected for the inulin-containing R2 broth.

The $\mathrm{R} 1$ medium containing $15 \%$ of $\mathrm{NaCl}$ proved to be strongly inhibitory for secondary metabolism (Fig. 3). No traces of secondary metabolites were detected in this case. Interestingly, the post-inoculation lag phase lasted much longer than for other performed bioreactor runs. The dissolved oxygen saturation level remained close to $100 \%$ until the third day of cultivation, when the growth phase was initiated. 
a

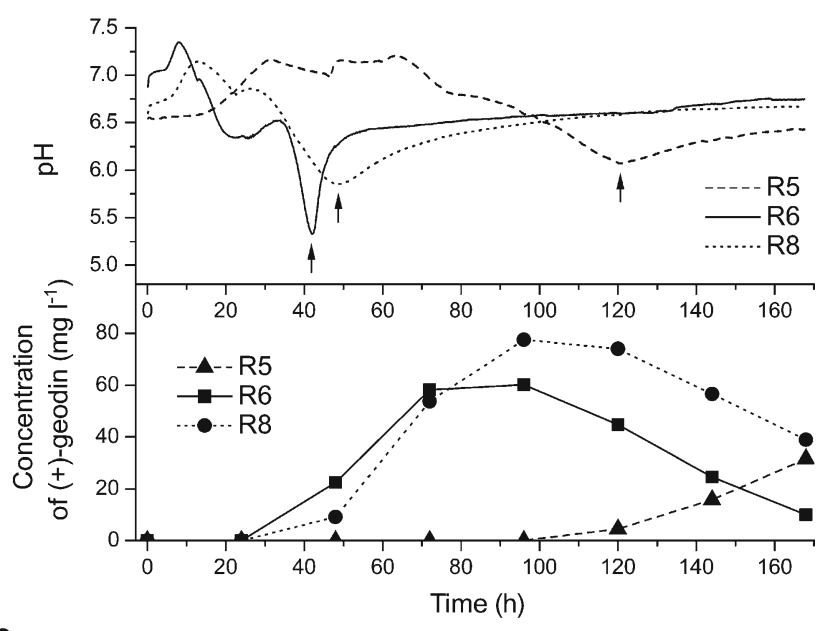

b

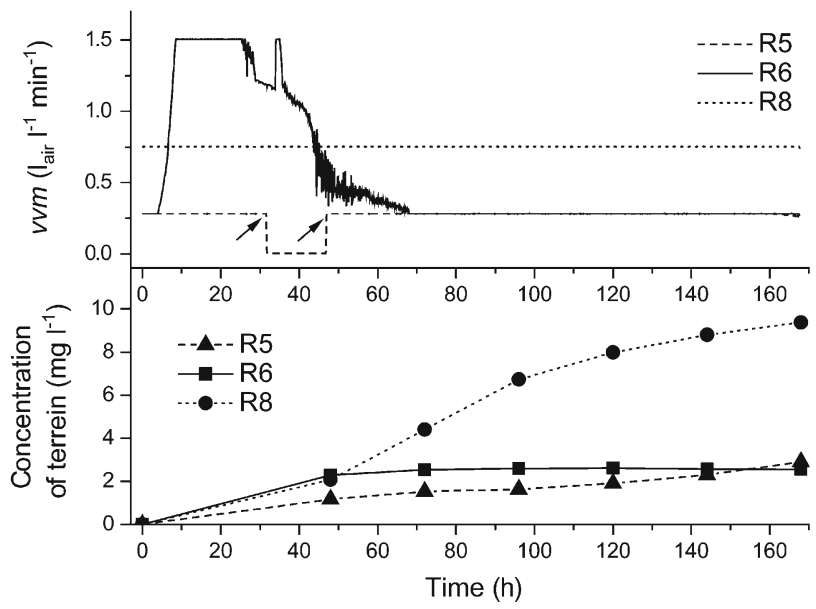

Fig. 4 Time courses of (a) (+)-geodin biosynthesis with respect to $\mathrm{pH}$ of the broth and (b) terrein production in terms of the observed $v v m$ (ratio of air flow rate and bioreactor volume). a The onset of (+)-geodin accumulation roughly corresponds to the inflection of $\mathrm{pH}$ observed in the corresponding culture (indicated by arrows). b The enhanced production of terrein in the $\mathrm{R} 8$ culture correlates with the period of relatively intensive aeration in R8. The 15-h-long shutdown of aeration during the $\mathrm{R} 5$ run is indicated by two arrows

Despite the survival of the fungus, the secondary metabolic pathways remained inactive throughout the cultivation period. The formation of exceptionally dense and compact pellets was observed for the R1 culture (Fig. 5).

The remaining metabolites were subjected to qualitative analysis. The presence of $4 \mathrm{a}, 5$-dihydromevinolinic acid and $3 \alpha$-hydroxy-3,5-dihydromonacolin $\mathrm{L}$ acid was detected in all examined cultures except the saline environment of R1. Dihydroisoflavipucine was found in all runs except the nitrogen-deficient R4 culture and the salt-rich R1 culture. The production of $(+)$-erdin, demethylasterric acid, and aspulvinone $\mathrm{E}$ was observed in the nitrogen-deficient culture R4 and oil-supplemented cultures R5, R6, R7, and R8. The presence of questin and sulochrin was revealed in the oilcontaining media R5, R6, R7, and R8. Finally, the significant

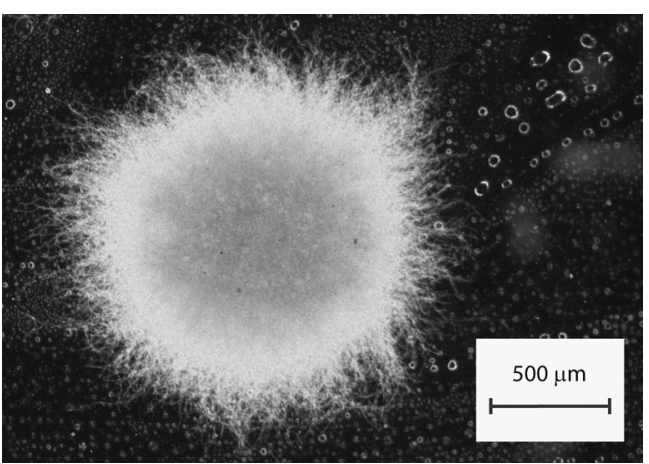

Fig. 5 Compact and dense morphology of fungal pellets observed in highly saline R1 culture

signals corresponding to desmethylsulochrin and (+)bisdechlorogeodin were detected solely under the oilenriched and chlorine-deficient conditions of R7.

\section{Discussion}

The main outcome of the study was the induction of biosynthesis of 15 secondary metabolites originating from six metabolic pathways of $A$. terreus (Fig. 6). To initiate the flux through the pathways, the corresponding parts of the genome needed to be activated by providing the required stimuli. This was attempted by the diversification of growth media and cultivation conditions. The collection of ESI+ and ESI- spectral data gathered in the course of analytical LC-MS analyses (Table 1; Figs. S1-S15) can be used as a resource in future experiments on A. terreus metabolism in the absence of authentic standards.

Fig. 6 Scheme of biosynthetic origins of secondary metabolites detected in bioreactor cultures of $A$. terreus ATCC 20542 based on the previously published works. The underlined names of molecules indicate the metabolites that were encountered in the course of the study. For clarity, some metabolic intermediates are not included in the scheme. Malonyl$\mathrm{CoA}$ is presented as the precursor of polyketide-type compounds (a), (b), (d), and (f), while 4-hydroxyphenylpyruvic acid fuels the formation of butyrolactone I (c) and aspulvinone E (e). a $3 \alpha$-Hydroxy-3,5dihydromonacolin $\mathrm{L}$ acid and mevinolinic acid originate from the common metabolic pathway (Barriuso et al. 2011; Kennedy et al. 1999). It is proposed here that $4 a, 5$-dihydromevinolinic acid may be formed via hydroxylation of 4a,5-dihydromonacolin $\mathrm{L}$ acid and subsequent esterification with methylbutyrate (reactions marked by question marks). f Eight of out 15 identified molecules have their origin in the common octaketide pathway (Chen et al. 1992; Nielsen et al. 2013). It is suggested here that (+)-erdin (Raistrick and Smith 1936) and demethylasterric acid (Natori and Nishikawa 1962) are the results of hydrolysis of ester bonds in $(+)$-geodin and asterric acid, respectively. Desmethylsulochrin is a precursor of sulochrin, but its presence can also be attributed to ester bond hydrolysis in sulochrin (not shown). The activity of biosynthetic pathways of (b) dihydroisoflavipucine (Gressler et al. 2011), (c) butyrolactone I (Guo et al. 2013), (d) terrein (Zaehle et al. 2014), and (e) aspulvinone E (Guo et al. 2013) have also been observed in the experiment 


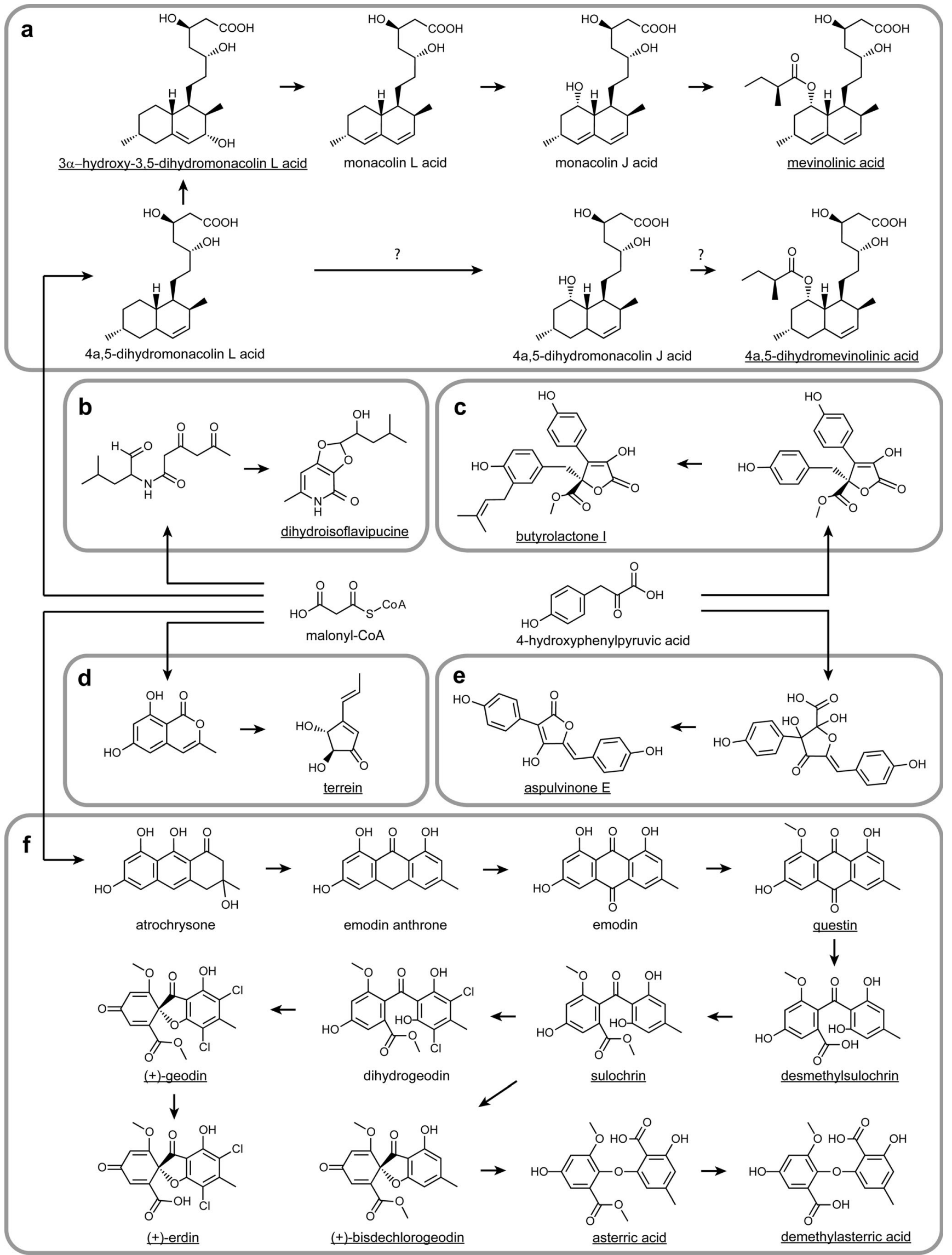


As expected, mevinolinic acid (Fig. 6a) was the major metabolite identified in the broth, with the relatively high concentration exceeding $100 \mathrm{mg} \mathrm{l}^{-1}$. Its formation is a result of coordinated action of two polyketide synthases and a set of post-PKS tailoring enzymes (Barriuso et al. 2011). $3 \alpha$-Hydroxy-3,5-dihydromonacolin L (Fig. 6a), another molecule detected in the study, was previously shown to originate from the same pathway (Nakamura et al. 1990; Treiber and Reamer 1989). The biosynthetic mechanism of $4 \mathrm{a}, 5$-dihydromevinolin formation has not been yet elucidated. It is suggested here that the formation of 4a,5-dihydromevinolin may be a result of single hydroxylation of 4a,5-dihydromonacolin $\mathrm{L}$ acid and further esterification with methylbutyrate (Fig. 6a).

The metabolite dihydroisoflavipucine (Fig. 6b) stems from the hybrid polyketide non-ribosomal peptide route involving malonyl-CoA and leucine as precursors (Gressler et al. 2011). The current study is the first report of dihydroisflavipucine formation by the strain $A$. terreus ATCC 20542. Another molecule, butyrolactone I (Fig. 6c), was described in a several strains of $A$. terreus (Nitta et al. 1983; Palonen et al. 2014; Rao et al. 2000), including a reisolate (Schimmel et al. 1998) and mutant (Schimmel and Parsons 1999) of A. terreus ATCC 20542. Its formation was proposed previously to originate from 4hydroxyphenylpyruvic acid and involved the catalytic activity of a non-ribosomal peptide synthetase-like enzyme (Guo et al. 2013). The detection of a polyketide compound derived from 6-hydroxymellein (Zaehle et al. 2014), namely terrein (Fig. 6d), was not surprising, since it was found in A. terreus ATCC 20542 agar cultures (Samson et al. 2011) and shake flask cultures (Boruta and Bizukojc 2014). The formation of aspulvinones was mentioned earlier for a number of A. terreus strains, including the ATCC 20542 strain cultivated on agar media (Samson et al. 2011). Since aspulvinone E (Fig. 6e) was proposed to be one of the early products of the biosynthetic pathway of aspulvinones (Guo et al. 2013), its presence in the examined bioreactor cultures confirmed the previously reported observations.

Eight metabolites identified in the study, namely questin, desmethylsulochrin, sulochrin, (+)-erdin, (+)bisdechlorogeodin, $(+)$-geodin, asterric acid, and demethylasterric acid (Fig. 6f), have their origin in the anthraquinone-related biosynthetic pathway (Chen et al. 1992; Nielsen et al. 2013). It is proposed here that demethylasterric acid (Curtis et al. 1960; Natori and Nishikawa 1962) and (+)-erdin (Raistrick and Smith 1936) result from hydrolysis of ester bonds in asterric acid and (+)geodin, respectively (Fig. 6f). It is unknown whether the presence of desmethylsulochrin in the broth can be attributed to hydrolysis of sulochrin or rather is a result of direct secretion of desmethylsulochrin, which in fact serves as a precursor for sulochrin in the sequence of biosynthetic steps leading from atrochrysone towards (+)-geodin (Fig. 6f). With regard to attained concentration values, $(+)$-geodin was confirmed here to be one of the major secondary metabolites produced by A. terreus ATCC 20542 (Askenazi et al. 2003; Bizukojc and Ledakowicz 2008). Furthermore, it is the first study that mentions demethylasterric acid as a molecule associated with A. terreus ATCC 20542.

The results of the study revealed the significant differences in the biosynthetic repertoire of $A$. terreus ATCC 20542 with regard to the applied bioprocess-related strategies. Notably, the bioreactor runs employing high concentration of $\mathrm{NaCl}$ (R1), addition of inulin (R2), and increased supply of yeast extract (R3) were characterized by relatively poor secondary metabolites production. The recent study of Abd Rahim et al. (2015) showed that the addition of $1 \mathrm{~g} \mathrm{l}^{-1} \mathrm{NaCl}$ enhances both lovastatin and (+)-geodin biosynthesis by $A$. terreus ATCC 20542 in glycerol-containing media. In the previous work of Tresner and Hayes (1971) regarding the $\mathrm{NaCl}$ tolerance of fungi, the two examined strains of $A$. terreus were shown to tolerate the $\mathrm{NaCl}$ levels even above $25 \%$. The concentration of $150 \mathrm{~g}^{-1}(15 \% \mathrm{w} / \mathrm{v}) \mathrm{NaCl}$ was chosen here to shock the fungal cells in a bioreactor culture. It turned out to be a very demanding environment for $A$. terreus ATCC 20542. The online measurements of dissolved oxygen saturation levels were monitored during the two initial days of cultivation, but there was no indication of entering the growth phase. At first, it was not clear whether the investigated culture was capable of adapting to this saline environment. However, osmoadaption did take place as the consumption of oxygen increased after the $48 \mathrm{~h}$ of cultivation indicating the start of the growth phase. Apparently, under the tested conditions, the strategy of survival assumed the shutdown of secondary metabolic pathways and investing the available biochemical resources into osmostress-related cellular functions (Duran et al. 2010). This was reflected by the observed morphology (Fig. 5). In comparison to the earlier reports (Bizukojc and Ledakowicz 2010; Gonciarz and Bizukojc 2014), the pellets formed in $15 \% \mathrm{NaCl}$ exhibited a remarkably compact and dense structure. This morphology indicated the minimization of contact area between the cells and the medium, what may be crucial for survival in these conditions. On the other hand, it also indicated the reduced transport of oxygen and nutrients into the pellet, what may be associated with the lack of secondary metabolic activity. In fact, this was the only bioreactor culture, for which there were no detected traces of secondary metabolites in the broth. The inhibitory effect of the added inulin and increased amount of nitrogen source was not as strong as for the high salt medium (Fig. 3). The deficiency of nitrogen source was reported previously to have a positive effect on lovastatin and (+)-geodin production by $A$. terreus ATCC 20542 (Bizukojc and Ledakowicz 2007, 2008). Notably, in contrast to other investigated compounds, dihydroisoflavipucine production was not observed in low- 
nitrogen R4 culture. The current study confirmed the importance of amino acids in the induction of dihydroisoflavipucine production described by Gressler et al. (2011). In the run R4, the deactivation of its biosynthetic pathway occurred due to the insufficient supply of yeast extract, which was a source of amino acids. The relatively high concentration of terrein in the nitrogen-deficient $\mathrm{R} 4$ culture confirmed the recent findings of Gressler et al. (2015) that nitrogen starvation induces terrein biosynthesis. However, under the conditions applied here, the stimulatory effect of rapeseed oil in the well-aerated culture $\mathrm{R} 8$ led to higher levels of terrein than those in the R4 run, as described below.

The addition of rapeseed oil, which is a mixture of saturated and unsaturated fatty acids, was shown to be an effective strategy to enhance the formation of secondary metabolites in A. terreus cultures. Among the quantified metabolites, the highest concentration values were reported either for R7 or R8 runs (Fig. 3), both of which involved the supplementation with oil. Its stimulating effect can be attributed to the increased supply of acetyl-CoA originating from $\beta$-oxidation of fatty acids, which in turn fuels the biosynthesis of malonyl-CoA and the downstream molecules (Fig. 6a, b, d, f). Another explanation is that linoleic acid present in rapeseed oil acts as a precursor of oxylipin, which elicits the quorum sensing responses in A. terreus and enhances the formation of secondary metabolites, as described by Sorrentino et al. (2010). Abd Rahim et al. (2015) reported previously that the supplementation with oleic acid elevates the concentration of lovastatin and (+)-geodin in A. terreus ATCC 20542 cultures cultivated with glycerol as the carbon source. It was also shown before that the addition of linoleic acid enhances lovastatin production by A. terreus (Sorrentino et al. 2010). The present study not only confirms the stimulatory effect of fatty acids on biosynthesis of lovastatin and (+)-geodin, but also indicates that the addition of oils can induce biosynthesis of a wide range of secondary metabolites.

The enhancing effect of rapeseed oil on secondary metabolism was investigated in combination with diversified aeration conditions in the bioreactor runs R5, R6, and R8. The R5 culture was maintained in the oxygen-deficient conditions. The shutdown of aeration for $15 \mathrm{~h}$ was performed in order to put the cells in the state of shock. According to the results, the oxygen-related stress did not trigger the formation of otherwise absent metabolites, nor did it increase the concentration of quantified molecules. In contrast, the aeration scheme implemented in the $\mathrm{R} 8$ run resulted in the highest concentration of (+)-geodin and terrein observed in the study (Fig. 3b, c). Maintaining relatively high and constant aeration rate throughout the idiophase proved to be beneficial for the production of these two metabolites. The correlation between the concentration of $(+)$-geodin and increased aeration rate was previously reported for $A$. terreus ATCC 20542 by Bizukojc and Ledakowicz (2008). Aeration rate and agitation speed were previously shown to influence the formation of terrein by A. terreus strain PF16 (Xu et al. 2012). Keeping the constant air flow and impeller speed turned out to be beneficial for terrein production by the PF16 strain. It agrees with the results obtained in the current study, as there was no oxygen level control in the R8 process and these two values were kept constant (see Fig. 1 and "Materials and methods" section for details). On the other hand, the production of terrein by the PF16 strain was positively influenced by decreasing both the aeration rate and agitation speed (Xu et al. 2012). This behavior was not observed for the ATCC 20542 strain, since air flow rate in the R8 run was higher than that in R5 and R6 cultures when the relatively high level of terrein biosynthesis was observed (Fig. 4b) and the stirrer speed in R8 was kept constant throughout the study at a relatively high level of $240 \mathrm{rpm}$. With regard to $\mathrm{pH}$ measurements in the runs R5, R6, and $\mathrm{R} 8$, the $\mathrm{pH}$ inflection points corresponding to the onset of $(+)$-geodin production confirm the observations made previously by Bizukojc and Ledakowicz (2008).

The addition of rapeseed oil was combined with minimization of chlorine content in the $\mathrm{R} 7$ culture. The residual amount of $\mathrm{Cl}^{-}$was expected to be present in the supplied yeast extract, but $\mathrm{NaCl}$ was present neither in the bioreactor culture nor in the corresponding preculture. This strategy was developed to provoke the reorganization of metabolic fluxes by simultaneously enhancing the activity of secondary pathways and establishing the conditions of chlorine deficiency. The effects of chlorine limitation on the secondary metabolic profile of A. terreus have not been reported previously. The limitation of a single element can lead to significant changes in secondary metabolome. For example, the production of patulin by Penicillium urticae was previously shown to be dependent on manganese supplementation and the accumulation of the pathway intermediate 6-methylsalicylic acid was reported for the manganese-deficient medium (Scott et al. 1984). In the current study, the limitation of chlorine led to the shutdown of (+)-geodin production, but the trace amounts of this metabolite were detected during the initial $48 \mathrm{~h}$ of cultivation. It reflected the fact that the residual amount of chlorine originating from yeast extract was utilized for $(+)$-geodin biosynthesis in the initial phase of growth and the biosynthetic route was deactivated as soon as the chlorine source was depleted. Similarly, only the weak signals corresponding to (+)-erdin were detected in the samples originating from the $\mathrm{R} 7$ culture. The shutdown of $(+)$-geodin and (+)-erdin formation in the absence of chlorine was anticipated, since these molecules have two chlorine atoms in their structure (Raistrick and Smith 1936). The blocking of (+)-geodin and (+)-erdin formation resulted in the intensified production of butyrolactone I, asterric acid, and mevinolinic acid (Fig. 3). Moreover, it led to the redirection of metabolic fluxes towards the formation of molecules that were not detected in other cultures, namely desmethylsulochrin and (+)-bisdechlorogeodin. The increased 
production of asterric acid can be explained by the promiscuity of dihydrogeodin oxidase, an enzyme responsible for the transformation of dihydrogeodin into $(+)$-geodin. Even though dihydrogeodin is a preferred substrate for this enzyme, it is also capable of oxidizing a structurally related compound, namely sulochrin, what leads to the formation of $(+)$ bisdechlorogeodin, a precursor of asterric acid (Fujii et al. 1987; Huang et al. 1996). In the absence of chlorine, dihydrogeodin was not formed and hence the catalytic activity of dihydrogeodin oxidase was limited to sulochrin oxidation.

For all the five quantified metabolites, their concentrations in the nitrogen-limited R4 culture were higher than those in the nitrogen-rich R3 culture (Fig. 3). It is likely that this effect is mediated by the global transcription factors AreA and AtfA encoded by the genes are $A$ and atf $A$, respectively, which were previously shown (Gressler et al. 2015) to be involved in the induction of terrein biosynthesis under nitrogen starvation.

The current study involved several strategies to induce biosynthesis of secondary metabolites by Aspergillus sp., some of which were not suggested before. This is the first report of testing oil supplementation under diverse aeration schemes and combining the inducing effect of oil with the single element (chlorine) deficiency to trigger biosynthetic pathways. The current study confirms that the previously suggested strategies based on the supplementation with fatty acids (Abd Rahim et al. 2015; Sorrentino et al. 2010) and the cultivation under nitrogen-limited conditions (Scherlach et al. 2011) are useful to uncover the secondary metabolic repertoire of filamentous fungi. While the diversification of carbon sources (Bode et al. 2002; Frisvad 2012) and the cultivation at high salt concentration (Wang et al. 2011) are established methods of inducing biosynthetic pathways, the addition of inulin and providing osmotic stress turned out to be ineffective under the conditions applied here.

In addition to suggesting general strategies to induce secondary metabolism in filamentous fungi, the study provided insights into the selective production of chosen metabolites. For instance, the results show that the oil supplementation under chlorine deficiency is a method to redirect the flux towards the production of asterric acid.

Even though the metabolites presented here, with the exception of lovastatin, are not the subjects of large-scale industrial production, their potential medical relevance remains an open question. The biological activity of these molecules is still a subject of research (Lee et al. 2002; Ohashi et al. 1992; Zaehle et al. 2014; Zhang et al. 2015). While the goal of the study was to induce biosynthesis of metabolites, the presented results are also relevant in the context of elimination of byproducts during lovastatin production.

In conclusion, A. terreus ATCC 20542 is capable of producing several structurally varied secondary metabolites in a stirred tank bioreactor. The activation of their biosynthesis is highly dependent on the medium composition and the applied cultivation strategy. Providing the stimuli associated with fatty acid supplementation, chlorine deficiency, and optimal aeration is an effective approach for the induction of secondary metabolites biosynthesis by the investigated strain. The culture of $A$. terreus ATCC 20542 remains viable in the liquid medium containing $15 \%$ of $\mathrm{NaCl}$, but the secondary metabolic pathways of the fungus are inoperative under these conditions.

Acknowledgments The project was funded by the National Science Centre (Poland) on the basis of the decision DEC-2013/11/N/ST8/ 00212. The authors wish to thank Prof. Dr. Isao Fujii, Iwate Medical University, Japan, for the kind gift of samples of secondary metabolites.

\section{Compliance with Ethical Standards}

Funding This study was funded by the National Science Centre (Poland) (grant number DEC-2013/11/N/ST8/00212).

Conflict of interest Tomasz Boruta declares that he has no conflict of interest. Marcin Bizukojc declares that he has no conflict of interest.

Ethical approval This article does not contain any studies with human participants or animals performed by any of the authors

Open Access This article is distributed under the terms of the Creative Commons Attribution 4.0 International License (http:// creativecommons.org/licenses/by/4.0/), which permits unrestricted use, distribution, and reproduction in any medium, provided you give appropriate credit to the original author(s) and the source, provide a link to the Creative Commons license, and indicate if changes were made.

\section{References}

Abd Rahim MH, Hasan H, Montoya A, Abbas A (2015) Lovastatin and $(+)$-geodin production by Aspergillus terreus from crude glycerol. Eng Life Sci 15:220-228

Albers-Schönberg G, Joshua H, Lopez MB, Hensens OD, Springer JP, Chen J, Ostrove S, Hoffman CH, Alberts AW, Patchett AA (1981) Dihydromevinolin, a potent hypocholesterolemic metabolite produced by Aspergillus terreus. J Antibiot (Tokyo) 34:507-512

Alberts AW, Chen J, Kuron G, Hunt V, Huff J, Hoffman C, Rothrock J, Lopez M, Joshua H, Harris E, Patchett A, Monaghan R, Currie S, Stapley E, Albers-Schonberg G, Hensens O, Hirshfield J, Hoogsteen K, Liesch J, Springer J (1980) Mevinolin: a highly potent competitive inhibitor of hydroxymethylglutaryl-coenzyme A reductase and a cholesterol-lowering agent. Proc Natl Acad Sci U S A 77:39573961

Askenazi M, Driggers EM, Holtzman DA, Norman TC, Iverson S, Zimmer DP, Boers M-E, Blomquist PR, Martinez EJ, Monreal AW, Feibelman TP, Mayorga ME, Maxon ME, Sykes K, Tobin JV, Cordero E, Salama SR, Trueheart J, Royer JC, Madden KT (2003) Integrating transcriptional and metabolite profiles to direct the engineering of lovastatin-producing fungal strains. Nat Biotechnol 21:150-156

Barriuso J, Nguyen DT, Li JWH, Roberts JN, MacNevin G, Chaytor JL, Marcus SL, Vederas JC, Ro DK (2011) Double oxidation of the cyclic nonaketide dihydromonacolin $\mathrm{L}$ to monacolin $\mathrm{J}$ by a single cytochrome P450 monooxygenase, LovA. J Am Chem Soc 133: 8078-8081 
Bergmann S, Schümann J, Scherlach K, Lange C, Brakhage AA, Hertweck C (2007) Genomics-driven discovery of PKS-NRPS hybrid metabolites from Aspergillus nidulans. Nat Chem Biol 3:213217

Bizukojc M, Ledakowicz S (2007) Simultaneous biosynthesis of (+)geodin by a lovastatin-producing fungus Aspergillus terreus. J Biotechnol 132:453-460

Bizukojc M, Ledakowicz S (2008) Biosynthesis of lovastatin and (+)geodin by Aspergillus terreus in batch and fed-batch culture in the stirred tank bioreactor. Biochem Eng J 42:198-207

Bizukojc M, Ledakowicz S (2010) The morphological and physiological evolution of Aspergillus terreus mycelium in the submerged culture and its relation to the formation of secondary metabolites. World $\mathrm{J}$ Microbiol Biotechnol 26:41-54

Bizukojc M, Pawlak M, Boruta T, Gonciarz J (2012) Effect of pH on biosynthesis of lovastatin and other secondary metabolites by Aspergillus terreus ATCC 20542. J Biotechnol 162:253-261

Bode HB, Bethe B, Höfs R, Zeeck A (2002) Big effects from small changes: possible ways to explore nature's chemical diversity. ChemBioChem 3:619-627

Bok JW, Ye R, Clevenger KD, Mead D, Wagner M, Krerowicz A, Albright JC, Goering AW, Thomas PM, Kelleher NL, Keller NP, Wu CC (2015) Fungal artificial chromosomes for mining of the fungal secondary metabolome. BMC Genomics 16:1-10

Boruta T, Bizukojc M (2014) Culture-based and sequence-based insights into biosynthesis of secondary metabolites by Aspergillus terreus ATCC 20542. J Biotechnol 175:53-62

Brakhage AA (1998) Molecular regulation of beta-lactam biosynthesis in filamentous fungi. Microbiol Mol Biol Rev 62:547-585

Brakhage AA (2013) Regulation of fungal secondary metabolism. Nat Rev Microbiol 11:21-32

Brakhage AA, Schroeckh V (2011) Fungal secondary metabolites - strategies to activate silent gene clusters. Fungal Genet Biol 48:15-22

Calam CT, Clutterbuck PW, Oxford AE, Raistrick H (1947) Studies on the biochemistry of micro-organisms: 74 . The molecular constitution of geodin and erdin, two chlorine-containing metabolic products of Aspergillus terreus Thom. Part 3. Possible structural formulae for geodin and erdin. Biochem J 41:458-463

Casas López JL, Sánchez Pérez JA, Fernández Sevilla JM, Acién Fernández FG, Molina Grima E, Chisti Y (2003) Production of lovastatin by Aspergillus terreus: effects of the C:N ratio and the principal nutrients on growth and metabolite production. Enzym Microb Technol 33:270-277

Chen ZG, Fujii I, Ebizuka Y, Sankawa U (1992) Emodin Omethyltransferase from Aspergillus terreus. Arch Microbiol 158: 29-34

Curtis RF, Hassall CH, Jones DW, Williams TW (1960) The biosynthesis of phenols. Part II. Asterric acid, a metabolic product of Aspergillus terreus Thom. J Chem Soc 4838-4842

Demain AL, Fang A (2000) The natural functions of secondary metabolites. Adv Biochem Eng Biotechnol 69:1-39

Duran R, Cary JW, Calvo AM (2010) Role of the osmotic stress regulatory pathway in morphogenesis and secondary metabolism in filamentous fungi. Toxins (Basel) 2:367-381

Frisvad JC (2012) Media and growth conditions for induction of secondary metabolite production. Methods Mol Biol 944:47-58

Fujii I, Iijima H, Tsukita S, Ebizuka Y, Sankawa U (1987) Purification and properties of dihydrogeodin oxidase from Aspergillus terreus. J Biochem 101:11-18

Gonciarz J, Bizukojc M (2014) Adding talc microparticles to Aspergillus terreus ATCC 20542 preculture decreases fungal pellet size and improves lovastatin production. Eng Life Sci 14:190-200

Gressler M, Zaehle C, Scherlach K, Hertweck C, Brock M (2011) Multifactorial induction of an orphan PKS-NRPS gene cluster in Aspergillus terreus. Chem Biol 18:198-209
Gressler M, Meyer F, Heine D, Hortschansky P, Hertweck C, Brock M (2015) Phytotoxin production in Aspergillus terreus is regulated by independent environmental signals. Elife 4:e07861

Guo CJ, Wang CCC (2014) Recent advances in genome mining of secondary metabolites in Aspergillus terreus. Front Microbiol 5:1-13

Guo CJ, Knox BP, Chiang YM, Lo HC, Sanchez JF, Lee KH, Oakley BR, Bruno KS, Wang CCC (2012) Molecular genetic characterization of a cluster in A. terreus for biosynthesis of the meroterpenoid terretonin. Org Lett 14:5684-5687

Guo CJ, Knox BP, Sanchez JF, Chiang YM, Bruno KS, Wang CCC (2013) Application of an efficient gene targeting system linking secondary metabolites to their biosynthetic genes in Aspergillus terreus. Org Lett 15:3562-3565

Huang K, Yoshida Y, Mikawa K, Fujii I, Ebizuka Y, Sankawa U (1996) Purification and characterization of sulochrin oxidase from Penicillium frequentans. Biol Pharm Bull 19:42-46

Keller NP, Turner G, Bennett JW (2005) Fungal secondary metabolismfrom biochemistry to genomics. Nat Rev Microbiol 3:937-947

Kennedy J, Auclair K, Kendrew SG, Park C, Vederas JC, Hutchinson CR (1999) Modulation of polyketide synthase activity by accessory proteins during lovastatin biosynthesis. Science 284:1368-1372

Laatsch H (2014) AntiBase 2014: the natural product identifier. Wiley$\mathrm{VCH}$, Weinheim

Lee HJ, Lee JH, Hwang BY, Kim HS, Lee JJ (2002) Fungal metabolites, asterric acid derivatives inhibit vascular endothelial growth factor (VEGF)-induced tube formation of HUVECs. J Antibiot (Tokyo) 55:552-556

Monaghan RL, Alberts RW, Hoffman CH, Albers-Schonberg G (1980) Hypocholesteremic fermentation products and process of preparation. US Patent 4231938

Nakamura T, Komagata D, Murakawa S, Sakai K, Endo A (1990) Isolation and biosynthesis of $3 \alpha$-hydroxy-3,5-dihydromonacolin L. J Antibiot (Tokyo) 43:1597-1600

Natori S, Nishikawa H (1962) Structures of osoic acids and related compounds, metabolites of Oospora sulphurea-ochracea v. Beyma. Chem Pharm Bull 10:117-124

Nielsen KF, Smedsgaard J (2003) Fungal metabolite screening: database of 474 mycotoxins and fungal metabolites for dereplication by standardised liquid chromatography-UV-mass spectrometry methodology. J Chromatogr A 1002:111-136

Nielsen MT, Nielsen JB, Anyaogu DC, Holm DK, Nielsen KF, Larsen TO, Mortensen UH (2013) Heterologous reconstitution of the intact geodin gene cluster in Aspergillus nidulans through a simple and versatile PCR based approach. PLoS One 8:e72871

Nitta K, Fujita N, Yoshimura T, Arai K, Yamamoto U (1983) Metabolic products of Aspergillus terreus. IX. Biosynthesis of butyrolactone derivatives isolated from strains IFO 8835 and 4100. Chem Pharm Bull (Tokyo) 31:1528-1533

Ochi K, Hosaka T (2013) New strategies for drug discovery: activation of silent or weakly expressed microbial gene clusters. Appl Microbiol Biotechnol 97:87-98

Ohashi H, Akiyama H, Nishikori K, Mochizuki J (1992) Asterric acid, a new endothelin binding inhibitor. J Antibiot (Tokyo) 45:1684-1685

Palonen E, Neffling M-R, Raina S, Brandt A, Keshavarz T, Meriluoto J, Soini J (2014) Butyrolactone I quantification from lovastatin producing Aspergillus terreus using tandem mass spectrometry-evidence of signalling functions. Microorganisms 2:111-127

Pavia DL, Lampman GM, Kriz GS, Vyvyan JR (2015) Introduction to spectroscopy. Cengage Learning, Boston

Raistrick H, Smith G (1936) Studies in the biochemistry of micro-organisms: the metabolic products of Aspergillus terreus Thom. Part II. Two new chlorine-containing mould metabolic products, geodin and erdin. Biochem J 30:1315-1322

Rao KV, Sadhukhan AK, Veerender M, Ravikumar V, Mohan EV, Dhanvantri SD, Sitaramkumar M, Babu JM, Vyas K, Reddy GO 
(2000) Butyrolactones from Aspergillus terreus. Chem Pharm Bull (Tokyo) 48:559-562

Roze LV, Chanda A, Wee J, Awad D, Linz JE (2011) Stress-related transcription factor AtfB integrates secondary metabolism with oxidative stress response in Aspergilli. J Biol Chem 286:35137-35148

Samson RA, Peterson SW, Frisvad JC, Varga J (2011) New species in Aspergillus section Terrei. Stud Mycol 69:39-55

Sarkar A, Funk AN, Scherlach K, Horn F, Schroeckh V, Chankhamjon P, Westermann M, Roth M, Brakhage AA, Hertweck C, Horn U (2012) Differential expression of silent polyketide biosynthesis gene clusters in chemostat cultures of Aspergillus nidulans. J Biotechnol 160:64-71

Scherlach K, Sarkar A, Schroeckh V, Dahse HM, Roth M, Brakhage AA, Horn U, Hertweck C (2011) Two induced fungal polyketide pathways converge into antiproliferative spiroanthrones. ChemBioChem 12:1836-1839

Schimmel TG, Parsons SJ (1999) High purity, high yield procedure for butyrolactone I production from Aspergillus terreus. Biotechnol Tech 13:379-384

Schimmel TG, Coffman AD, Parsons SJ (1998) Effect of butyrolactone I on the producing fungus, Aspergillus terreus. Appl Environ Microbiol 64:3707-3712

Scott RE, Jones A, Gaucher GM (1984) A manganese requirement for patulin biosynthesis by cultures of Penicillium urticae. Biotechnol Lett 6:231-236

Seto S (1979) Biosynthesis of aspulvinones, metabolites of Aspergillus terreus. Int Congr Pure Appl Chem (Proc) 4:A21-A31

Sorrentino F, Roy I, Keshavarz T (2010) Impact of linoleic acid supplementation on lovastatin production in Aspergillus terreus cultures. Appl Microbiol Biotechnol 88:65-73
Tobert JA (2003) Lovastatin and beyond: the history of the HMG-CoA reductase inhibitors. Nat Rev Drug Discov 2:517-526

Treiber LR, Reamer RA (1989) Origin of monacolin L from Aspergillus terreus cultures. J Antibiot (Tokyo) 42:30-36

Tresner HD, Hayes JA (1971) Sodium chloride tolerance of terrestrial fungi. Appl Microbiol 22:210-213

Vinci VA, Hoerner TD, Coffman AD, Schimmel TG, Dabora RL, Kirpekar AC, Ruby CL, Stieber RW (1991) Mutants of a lovastatin-hyperproducing Aspergillus terreus deficient in the production of sulochrin. J Ind Microbiol 8:113-119

Wang Y, Zheng J, Liu P, Wang W, Zhu W (2011) Three new compounds from Aspergillus terreus PT06-2 grown in a high salt medium. Mar Drugs 9:1368-1378

Xu B, Yin Y, Zhang F, Li Z, Wang L (2012) Operating conditions optimization for $(+)$-terrein production in a stirred bioreactor by Aspergillus terreus strain PF-26 from marine sponge Phakellia fusca. Bioprocess Biosyst Eng 35:1651-1655

Yin W-B, Reinke AW, Szilágyi M, Emri T, Chiang Y-M, Keating AE, Pócsi I, Wang CCC, Keller NP (2013) bZIP transcription factors affecting secondary metabolism, sexual development and stress responses in Aspergillus nidulans. Microbiology 159:77-88

Zaehle C, Gressler M, Shelest E, Geib E, Hertweck C, Brock M (2014) Terrein biosynthesis in Aspergillus terreus and its impact on phytotoxicity. Chem Biol 21:719-731

Zhang F, Mijiti M, Ding W, Song J, Yin Y, Sun W, Li Z (2015) (+)-Terrein inhibits human hepatoma Bel-7402 proliferation through cell cycle arrest. Oncol Rep 33:1191-1200

Zhou Y (2012) Isolation and structure elucidation of bioactive secondary metabolites from the sponge-associated fungus Aspergillus sp. Dissertation, Heinrich-Heine-Universität Düsseldorf 